\title{
The Impact of Using Online Educational Tools on Science Learning among Students
}

DOI: https://doi.org/10.47175/rielsj.v1i2.78

\section{| Morteza Bakhtiarvand |}

\author{
Ph.D.student of Educational \\ Technology, Department of \\ Educational Technology, \\ Faculty of Psychology and \\ Education, Allameh \\ Tabataba'i University, Tehran, \\ 1489684511, Iran
}

m_bakhtiarvand@yahoo.com

\begin{abstract}
The present study aims to investigate the effect of using online educational tools on science learning among male students in the fifth year of primary school in Shahriyar city. Research method is semi-experimental based on pre-test - post-test design. All male students in the six year of primary school at Shahriyar city in the academic year 2016-17 that 260 of them were selected by random sampling. First, pages from the book of science without the use of educational tools in all classes are taught and filled researchermade inventory of science learning (reliability of learning inventory using Cronbach's alpha coefficient was calculated and was used to assess the validity of the content from the point of view of primary school teachers and professors and experts). Then other pages of the math book using educational tools in 5 sessions of 30-minute was done supervised by teachers and researchers for all classes. Having the project been completed, researcher-made learning questionnaire was again conducted equal to the first questionnaire for all classes. And to analyze the assumptions, gamma test in agreement tables and non-parametric Spearman correlation test using SPSS software version 20 was conducted. The results showed that the active use of educational tools leads to a significant difference in science learning in students.

KEYWORDS

Online Educational Tools; Science Learning; Male Students; Primary schools
\end{abstract}

\section{INTRODUCTION}

Human, the most complete and most advanced creature on earth, is the most powerless and the most helpless at birth and with the greatest talent is able to learn from their experience as best as possible and the responses and experiences learnt constitute his/her most behavioral reservoir. Learning forms the basis of people's behavior and they become familiar with the environment through learning, learn how to emit emotions and develop their rationality. Attention to the "Principles of Learning" in training activities is the essential condition for the success of lecturers (Mahdavi Qa'ravi). Various definitions have been made of learning, but almost the perfect definition was made by Hilgard that include making relatively constant changes in the potential behavior of learner that this change is resulted from getting experiences. Behaviorist defined learning as changes in visible and measurable changes behavior. But from the perspective of Gestalt school, learning is gaining new insights or changes in the past insights. Learning or any insight to be defined constitutes the basis of human behavior and the first specific attribute of it is change. Changes that occur gradually is relatively stable and is achieved by the experience. Hilgard and Marquis defined learning as learning is the changes that is created in the subjective structure of people and currently is not 
measurable. Some of the changes resulted from learning may be turned into an actual behavior due to favorable conditions that is so called function.

Education in each country plays an important role in individual and social behavior of individuals. In fact, the educational activities of each country can be an investment for the next generation that aims for human development. In other words, the purpose of education is to raise awareness and human potential. Given the wide scope and coverage of the activities of the educational system, it is necessary to use the best methods to improve the quality of education in the design and implementation of its activities. Mathematics is one of the most important and basic courses in learners' academic years. This importance is due to the fact that studying mathematics helps one's life and the society they live in. However, despite the importance of this lesson, it is often observed that students are not interested in, and sometimes hateful of, it's learning. Although mathematics in Iranian schools is not much different from the mathematics in developed countries in terms of content, it is different from them in terms of targets, approach, strategy, methods and techniques of teaching mathematics. In our schools, math scores is the criterion for identifying the weak and strong students. In the past, though not as extensive as modern times, training tools were used. Even the record of its usage, according to Sattler, dates back to fifth period before Christ. He maintains that sophists were the pioneers in the use of educational technology. History indicates much changes in educational tools in different periods. With each generation, tools, traditions and new ideas grow and this issue has a special place at the beginning of the twentieth century. Social, economic and political systems are changing and new tools are led to the creation of new methods and challenges in human thought and new thoughts are born with this challenge and as a result various systems compatible with new social needs can be created. Human communities are changing and developing with an amazing speed and these changes cover different aspects of life. Development of new science and technology raises new knowledge that creates new needs for humans. Therefore, training should be done with greater speed and quality. For this reason, many psychologists and experts recommend the use of educational tools in issues of education (Saberi, 2003).

Including those who caused fundamental change in education system both in method and content is "Jean-Jacques Rousseau" and among those who inspired by Rousseau is "Pestalozzi". Among those who used educational tools in a broad sense are Froebel, Montessori Surrey, Thorndike, John Dewey, etc. who played a main role in the development of meaning tools and educational technology and closing it to its current meaning. That's why, tools and training materials, including simple and complex, are used as a tool to facilitate teaching and learning in education systems. These devices are important in this respect that theory and practice are combined and coordinated with each other and leads to lasting learning and diversity in the classroom as part of their special status.

With regard to scientific and technological progress in the present age, educational tools as an association have been able to play its role well. Due to scientific and technological advances in the present era, the necessary and status of elementary mathematics is more and more felt. Since the first period of official training of every human being is primary education, the students learn in this course what they want and their learning depends on their education condition. Obviously, if teachers have the necessary skills to use these devices, their effectiveness will be increased. In fact, how to achieve learning is specified with the use of the tools and processes used to achieve educational goals.

Despite real progress occurred in mathematics education, very little change has been occurred in the mathematics classroom (National Council of Teachers of Mathematics, 2000, Lehrer, 2000). Also, the findings of the Third International Mathematics and Science Study 
(Thames) makes clear truths for our education system that third and fourth grade students in third grade math test have obtained rank 24 among 24 countries and in the fourth grade, they have obtained rank 25 among 26 countries. Thames studies for our education has had two functions (Hourizadeh: 2006). First, it indicates how we have failed to achieve the objectives and second, it makes possible to investigate the causes and risk factors in failures especially with respect to other systems of education (Hourizadeh, 2006). It is important that the emphasis on the traditional and expired methods in education, resistance to change and innovation and lack of attention to research results in the field of education are among the issues that caused our education system fall behind in the competition arena (Gouya, 2006). On the other hand, creating change and innovation in one specific area and in one aspect cannot be sufficient, but it is the full attention to all sectors involved in education and noncompatibility that can have the greatest impact (Bazargan, 2007).

As mentioned, learning with a deep understanding makes communication between existing knowledge and new knowledge significantly, when students can make a relationship between mathematical ideas, their understanding will be deeper and more lasting. They can observe connections between mathematical topics, between mathematics and other related subjects and between their interests and experiences. Students also learn mathematical coherence and unity through training that focuses on the interconnectedness of mathematical ideas. Mathematics is not a series of separated fields that sometimes is taken apart and is presented through this method.

An educational strategy that focuses on the relationships between concepts and help us achieve to strong principles is to use educational tools at various stages of the educational process. Today, for clarifying education, diversify the education process and making the teaching materials clear, the use of educational tools by teachers is inevitable. Students make learning and teaching process objective using educational materials and easily learned new teaching in the process of learning process. Educational tools provide the necessary context for learning among students extensively (Razmtalab, 2009). According to the findings in psychology of learning, students learn teaching materials better and more comfortable though observation and using various instruments, for educational tools make education more realistic and more and more pleasant due to activating various senses of students (Abbasi, 1992). Participation of students in the learning process makes mathematical learning more attractive (Alamo alhoda, 2002). Also, the attitudes and perceptions influence the ability of learners in the learning (Aghazadeh, 2009). When the subject is valuable for students, the amount of their learning and functions in that field is far more than the issues that not much attention is given to it (Ashcroft, 2001). It is worth noting that the emotional aspect in learning is very important (Gavalkova, 2008).

Due to constraints in the supply of human resources for education, the use of new educational tools as a way to achieve the goal of providing equal educational opportunity is considered and the reasons for the use of educational tools have been mentioned under topics such as the educational problems and difficulties, the role of senses in learning, the role of tools and materials in learning and teaching. The results of research show that countries that have used new educational technology reasonably and appropriately have eliminated or reduced most of their training problems (Abbasi, 1992). Repeated observations show the fact that continuous and desirable use of educational tools is not conducted (Ali Abadi, 2009). The use of educational tools require great effort and many teachers are not willing to work hard themselves to become more experienced in their works and many others fail to understand that the methods they use have not real performance (Clark, 2001). If the educational means are used as a tool to facilitate learning, it will play an important role in teaching mathematics. Teaching tools facilitate learning the mathematical materials among students because of the 
combination of theory and practice and causes the durability of the material in mind. Using educational tools, students are actively exploring the relationships and concepts and make their learning process objective in the face of their problems and this issue eliminates fear of mathematics in students and make the teaching and learning process enjoyable for them. Therefore, students will have more insistence to learn and easily are involved in learning new materials during teaching. The use of educational tools can play an important role in creating a positive attitude in students and students with a positive attitude about math concepts can have further progress in learning.

The main purpose of this research is to study the effective and active use of fifth grade students of online educational tools in their learning science.

\section{Hypothesis}

Active use of online educational tools causes increasing scince learning among fifth year of primary school students in Shahriyar city.

\section{Population, sample and sampling methods}

The research method here is semi-experimental based on pre-test - post-test design. The statistical population in this study includes all fifth grade boys attended in elementary school in the city of Shahriyar in the academic year 2016-17 that 260 people were chosen in simple random sampling.

\section{Research Tool}

Researcher-made science learning questionnaire: this questionnaire includes 32 items, 5 options (completely disagree, disagree, indifferent, agree, completely agree") from strongly disagree (score 1) to strongly agree (score 5). In this research, using 260 fifth grade male students, the effect of active use of students' online educational tools on mathematical learning has been investigated. In the present study, the reliability coefficient of this tool was calculated using Cronbach's alpha, that the amount of alpha is achieved 0.96.

\section{Descriptive Findings}

Table 1. frequency distribution of students' opinions before and after active use of online educational tools

\begin{tabular}{|c|c|c|c|c|c|c|c|}
\hline \multicolumn{2}{|c|}{$\begin{array}{l}\text { After education/before } \\
\text { education }\end{array}$} & $\begin{array}{l}\text { Strongly } \\
\text { disagree }\end{array}$ & Disagree & $\begin{array}{c}\text { To } \\
\text { some }\end{array}$ & Agree & $\begin{array}{c}\text { Completely } \\
\text { agree }\end{array}$ & Total \\
\hline \multirow{2}{*}{$\begin{array}{l}\text { Strongly } \\
\text { disagree }\end{array}$} & Number & 157 & 178 & 107 & 49 & 65 & 556 \\
\hline & Percentage & 2.4 & 2.7 & 1.6 & 0.7 & 1 & 8.4 \\
\hline \multirow{2}{*}{ Disagree } & Number & 213 & 273 & 163 & 97 & 114 & 860 \\
\hline & Percentage & 3.2 & 4.1 & 2.5 & 1.5 & 1.7 & 13 \\
\hline \multirow{2}{*}{$\begin{array}{r}\text { To some } \\
\text { extent }\end{array}$} & Number & 236 & 256 & 299 & 254 & 334 & 1379 \\
\hline & Percentage & 3.6 & 3.9 & 4.5 & 3.9 & 5 & 20.9 \\
\hline \multirow[t]{2}{*}{ Agree } & Number & 382 & 394 & 467 & 394 & 452 & 2089 \\
\hline & Percentage & 5.8 & 6 & 7 & 6 & 6.9 & 31.7 \\
\hline
\end{tabular}




\begin{tabular}{|c|l|l|l|l|l|l|l|}
\hline \multirow{2}{*}{$\begin{array}{c}\text { Completely } \\
\text { agree }\end{array}$} & Number & $\mathbf{2 7 0}$ & $\mathbf{3 5 0}$ & $\mathbf{3 3 1}$ & $\mathbf{3 7 2}$ & $\mathbf{3 8 0}$ & $\mathbf{1 7 0 3}$ \\
\cline { 2 - 7 } & Percentage & 4.1 & $\mathbf{5 . 3}$ & $\mathbf{5}$ & $\mathbf{5 . 7}$ & $\mathbf{5 . 8}$ & $\mathbf{2 5 . 9}$ \\
\hline \multirow{2}{*}{ Total } & Number & $\mathbf{1 2 5 8}$ & $\mathbf{1 4 5 1}$ & $\mathbf{1 3 6 7}$ & $\mathbf{1 1 6 6}$ & $\mathbf{1 3 4 5}$ & $\mathbf{6 5 8 7}$ \\
\cline { 2 - 8 } & Percentage & 19.1 & 22 & $\mathbf{2 0 . 8}$ & $\mathbf{1 7 . 7}$ & $\mathbf{2 0 . 4}$ & $\mathbf{1 0 0}$ \\
\hline
\end{tabular}

The results achieved in Table 1 shows frequency distribution that regarding scince learning, after training in $21 \%$ (i.e. 270.1258), all questions of students' opinions has been changed from strongly disagree to completely agree. Also, in $25 \%$ of total questions (i.e. 350.1451 ), respondents' opinions has been changed from totally disagree to completely agree. This ratio to change the opinion from totally disagree to agree and from disagree to agree has been $31 \%$ (382.1251) and 21\% (394.1451), which represents a positive change in the opinions after applying the online educational tools.

\section{Inferential Findings}

The research hypothesis is: the active use of online educational tools will increase the learning of science in the fifth grade elementary school boys. Gamma statistic is a criterion to assess the link or correlation between two category or sequence variable that varies between -1 to 1 . Absolute values close to one indicates a strong link between ordinal variables and values close to zero shows no link between the two variables.

Table 2. Gamma test results on learning science among primary students

\begin{tabular}{|c|c|c|c|c|}
\hline Questionnaire & Gamma & $\begin{array}{c}\text { Standard } \\
\text { deviation }\end{array}$ & T-statistics & Significance level \\
\hline Learning & $\mathbf{0 / 1 3 6}$ & $\mathbf{0 / 0 1 2}$ & $\mathbf{1 0 / 9}$ & $\mathbf{0 . 0 0 0}$ \\
\hline
\end{tabular}

Results of Table 2 shows that active use of online educational tools from the point of view of elementary school girls of Shahriyar city has statistically significant impact on their learning (significance level of the test equals 0.00 that is less than 0.05) and gamma coefficients equals 0.136 that is positive and shows that learning has been increased in them.

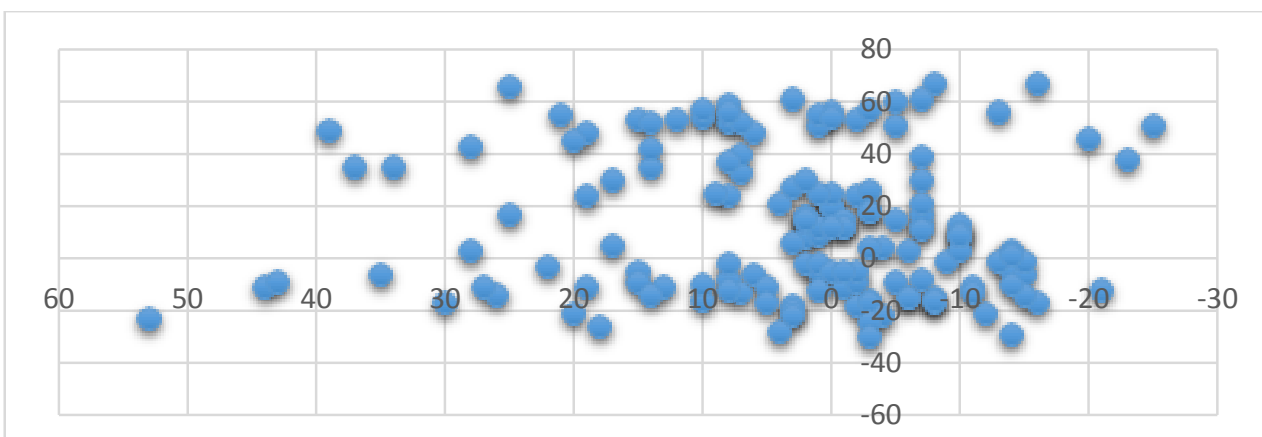

Figure 1. Different learning distribution curve before and after the active use of online training tools

\section{DISCUSSION AND CONCLUSION}

The findings of this study showed that the use of educational tools in mathematics can help students solve math problems. These findings are compatible with the results of the research done by Safavi (1970), indicating the use of useful and educational tools that students 
interested in as a group work will enhance their learning and academic achievement. Also Grant (1998) concluded in his research that students who have benefited from objective educational materials show more accurate and deeper mathematical learning and sometimes have more incentive to do their tasks, better understand mathematical ideas and apply these thoughts better in their lives. Abbaszadeh (1984) concluded in his study that educational tools play a main role in education and will lead to increased learning. In explaining this findings, Hajipour and Parwin (1988) concluded in their studies that making use of educational tools causes students are engaged with course content, get out of a passive mode, his/her feelings are engaged with course content and this challenge between the student and course content cause learning and enhanced academic performance. In their study entitled the effectiveness of the implementation of video in learning mathematics in Isfahan, Yazdchi and Dr. Zamani (2002) conceded that the amount of learning among the students who receive training from the tutor along with illustrative design is more than that of the students who make benefit from tutor training without the use of illustrative design and generally mathematics is learnt not only through hearing and seeing, but also through the sense of touch and sense of tactility. Only $30 \%$ of subjects are taught through conventional teaching, while if learning is done through appropriate use of educational tools, students' learning will be raised up to $75 \%$ (Akrami Abarghouie, 2003).

Using an integrated educational tools, students not only learn how to read, write and solve math but how to research, create new knowledge and solve problems in the new century is certainly waiting for them to learn.

Taking an accurate look at the educational system of the country, we will see that unfortunately the common approach for teaching concepts is the dominant approach in most schools. This approach is based on the accumulation of memories in mind, learning in the mnemonic method and the dependency on the resources of books and teachers. (Yousefi, Khayer. 2003). Also, the results of several studies suggests lack of sufficient knowledge of instructional media, lack of knowledge about the real meaning of educational technology, the traditional method used for ease of teachers, lack of sufficient scientific trainings in universities (Esfandiari, 2003, cited from Jafarinejad, 2003). Issues of financial problems, the volume of textbooks, lack of laboratories and workshops, mismatch between the materials and the number of students and the lack of a valuation system of how to use teachers' educational materials are the deterrents factors in the use of educational tools in education and learning process. Experiences shows that most math teachers are not willing to use the educational tools in their teaching for various reasons, including time constraints and lack of sufficient time, class size and lack of sufficient tools as well as lack of awareness and it is necessary to make efforts that the country's educational system is inclined towards how to think instead of merely thinking.

Teachers should provide conditions in classroom that students can learn with more interest in a dynamic environment. In fact, teachers should encourage students to discover principles and concepts and avoid direct response to students' questions. Teachers should allow students to present their responses, though faulty, and then seek to eliminate defects and mistakes in responses by the help of students. Note, however, teachers must be patient in these methods. Teachers should always consider cognitive development of students and their learning styles and accordingly establish fitness between students' ability and presenting the related concepts and express educational materials using proper equipment and tools and at the end focus on general conclusion based on reasoning and science symbols. 


\section{REFERENCES}

Aghazadeh, M. (2005). Guide to new methods of teaching. $4^{\text {th }}$ edition, Tehran, Iran: Avij.

Ashraf, M. (2011). Effects of teaching numbers concept page on students' mathematical progress with and without inabilities in mathematical learning. Journal of Special Education, (10)7,112-123

Akrami Abarghouie, A. (2003). Methods of creativity teaching to students. Journal of mathematics education, teacher development .2(1), 100-111.

Bazargan, Z. (2007). Another school. Tehran: the Association of parents and educators of the Islamic Republic.

Jafarnejad, A. (2003). The causes main 9reasons of implementing educational tools and their impacts in teaching and learning process among high school students in Mazandaran province. Reporting research project. Management and Planning Organization.

Hajipour, P. (1988). Surveying the necessity of using various means of education in schools. Keyhan magazine, 1(16), 23-34.

Davis, I. (1993). Learning management. Translated by Dariush Norouzi and Mohammad Hasan Amir Teimouri (1982), Iran, Tehran: Farhang

Razmtalab, N. (2009). The role of educational technology in learning. Educational Articles, 2(3), 3-14.

Saberi, M. (2003). The place of necessity and applying modern education technology in higher education, Proceedings of the conference on the use of educational technology in higher education, 2-3 November, University of Arak, p 309.

Safavi, A. (1970). Generality and techniques of teaching. Tehran: Moaaser Publication.

Abbasi, P (1982), investigating and studying how high school teachers use educational-aid tools, Journal of Education, 8 (4), 79-96.

Alam al-Hoda, S. (2002). New strategies in teaching mathematics. Tehran: Iran methods.

Ali Abadi, Kh. (2009). An introduction to educational technology. Tehran, Iran: Payam Noor.

Gouya, Z. (2006). Math problem solving. Math education Journal. 2(24), 4-18.

Yazdchi, S. \& Zamani, B. (2002). The effectiveness of using video design in learning math projects in Isfahan city. Journal of Amouzeh, 16, 65-75.

Yousefi, F. \& Khayer, M. (2003). Relationship between formal reasoning, emotional intelligence and academic achievement in a group of gifted and regular students in Shiraz. Journal of the Science of Educational Psychology, 33 (2), 177-202.

Ashcraft, M. H., \& Kirk, E. P. (2001). The Relationships among working memory, math anxiety, and performance. Journal of Experimental Psychology, 130(2), 224-237.

Clark, J.H. (2001). Patterns of Thinking Intergrading Learning Skills in Content Teaching. Boston: Allyn and Bacon.

Gavalcova, T. (2008). On strategies contributing to active learning. Teaching Mathematics and ITS Applications.

Garnett. K. (1998)."Math learning Disabilities". www.idonline.org/article/5896 